\title{
The Early Nodulin Gene MtN6 Is a Novel Marker for Events Preceding Infection of Medicago truncatula Roots by Sinorhizobium meliloti
}

\author{
R. Mathis, C. Grosjean, F. de Billy, T. Huguet, and P. Gamas \\ Laboratoire de Biologie Moléculaire des Relations Plantes-Microorganismes, CNRS-INRA, BP 27, 31326 \\ Castanet-Tolosan Cédex, France \\ Accepted 8 March 1999.
}

\begin{abstract}
MtN6 belongs to a series of cDNA clones representing Medicago truncatula genes transcriptionally activated during nodulation by Sinorhizobium meliloti (P. Gamas, F. de Carvalho Niebel, N. Lescure, and J. V. Cullimore, Mol. Plant-Microbe Interact. 9:233-242, 1996). We show here by in situ hybridization that MtN6 transcripts specifically accumulate first at very localized regions in the outer root cell layers, corresponding to outer cortical cells containing preinfection threads. At later stages, MtN6 expression is observed ahead of growing infection threads, including in the infection zone of mature root nodules. Interestingly, regulation of MtN6 is clearly distinct from that of other early nodulins expressed in the same region of the nodule, in terms of response to bacterial symbiotic mutants and to purified Nod factors. We thus suggest that MtN6 represents the first specific marker of a pathway involved in preparation to infection, which is at least partly controlled by Nod factors. Finally, we discuss the intriguing sequence homology shown by MtN6 to a protein from Emericella (Aspergillus) nidulans, FluG, that plays a key role in controlling the organogenesis of conidiophores (B. N. Lee and T. H. Adams, Genes Dev. 8:641-651, 1994).
\end{abstract}

Additional keywords: development, legume, symbiotic interaction.

The rhizobia-legume symbiotic interaction represents a very rich experimental system for several major issues of plant developmental biology, such as perception/transduction of molecular signals or control of organogenesis processes. Indeed, following the exchange of specific signals between the macroand microsymbionts, a new organ can develop in legumes, the root nodule, in which atmospheric nitrogen fixation can take place (for review see Mylona et al. 1995). Critical in this process are the recognition by the plant of lipo-chitooligosaccharides produced by the bacteria, the Nod factors (see reviews by Dénarié et al. 1996; Heidstra and Bisseling 1996; Long 1996; Schultze and Kondorosi 1996; Spaink 1996), and

Corresponding author: P. Gamas; Fax: (33) 561-28-50-61

E-mail: gamas@toulouse.inra.fr

Nucleotide and/or amino acid sequence data are to be found at the EMBL data base as accession numbers Y18225 (MtN6 cDNA) and AJ133118 (MtN6 gene). the nutritional status of the host plant, which must be nitrogen starved to be fully responsive (Heidstra et al. 1997 and references therein).

Different stages can be distinguished during nodulation (for reviews see Hirsch 1992; Kijne 1992). During the preinfection stage (approximately the first 2 days following $\mathrm{Si}$ norhizobium meliloti inoculation, in Medicago truncatula) root hair, epidermal, cortical, and pericycle cells respond to Nod factors (Heidstra and Bisseling 1996), notably by root hair deformation, and reactivation of the cell cycle in cortical cells (Yang et al. 1994). In temperate legumes, such as Pisum sativum or M. truncatula, cortical cell activation leads to the formation of division foci, the nodule primordia, located in the inner cortex, and of cytoplasmic bridges, also called preinfection threads (van Brussel et al. 1992), in the outer cortex. This takes place at defined locations in the root, opposite protoxylem poles, suggesting the involvement of positional cues derived from the stele (for review see Cohn et al. 1998). A following stage (about 3 days after inoculation) is the establishment in the primordium of a meristem, responsible for the development of the nodule structure. In the mean time, bacterial infection takes place by tubular structures, the infection threads, that form by invagination of the root hair cell wall about 2 days after inoculation and then grow down toward the nodule primordium, following the pathway defined by the cytoplasmic bridges. Infection is not required for nodule organogenesis, since empty (noninfected) nodules can be formed in response to bacterial exo mutants (deficient for exopolysaccharide production; Cheng and Walker 1998 and references therein), or spontaneously in some genotypes of nitrogenstarved $M$. sativa plants (NAR nodules, for nodulation in the absence of Rhizobium; Truchet et al. 1989). Infection is important, however, for the differentiation of several of the central tissues found in mature indeterminate nodules, which consist of, successively, the distal meristematic zone I, the infection zone II, the amyloplast-rich interzone II-III, the nitrogen-fixing zone III, and finally the proximal senescence zone IV. These tissues are surrounded by peripheral tissues, which include the vascularized nodule parenchyma, the nodule endodermis, and the nodule cortex (Vasse et al. 1990).

The nodulation process is accompanied by the induction of certain genes, termed nodulin genes, classified as early or late 
depending on their kinetics of expression (for review see Pawlowski 1997). Many of these genes have been identified in several legume species, and cloned by a variety of approaches (see for recent publications Cook et al. 1995; de Carvalho Niebel et al. 1998; Frugier et al. 1998; Gamas et al. 1996; Goormachtig et al. 1995; Greene et al. 1998; Heidstra et al. 1997; Szczyglowski et al. 1997). Several of them have been exploited to characterize different nodulation stages essentially at the regulation level (see for recent publications Bauer et al. 1997; Coba de la Peña et al. 1997; Heidstra et al. 1997; Gamas et al. 1998; Goormachtig et al. 1998; Pingret et al. 1998; van Rhijn et al. 1997 ), the challenge for coming years being to identify key players and understand their mode of action.

We previously published the identification of a series of cDNA clones representing $M$. truncatula genes transcriptionally activated during nodulation by $S$. meliloti that were designated MtN genes (Gamas et al. 1996). We decided to characterize in more detail one of them, MtN6, because partial sequencing revealed an intriguing homology to a protein from Emericella (Aspergillus) nidulans, FluG, that plays a key role in the control of a particular developmental process, the organogenesis of conidiophores (Lee and Adams 1994, 1995). We show in this paper that MtN6 represents a novel marker of nodulation associated with preinfection events, and its regulation appears to be distinct from those described for other known early nodulins.

\section{RESULTS}

\section{MtN6 is homologous to the N-terminal domain of the Emericella nidulans FluG protein.}

Figure 1A shows the complete DNA sequence of the MtN6 cDNA clone, found to be 1,454 bp long and thus approximately full size, considering the length of transcripts detected with an MtN6 probe on Northern (RNA) blots (about $1.6 \mathrm{~kb}$ ). We were able to find a corresponding genomic clone (partly shown in Figure 1B), $7.5 \mathrm{~kb}$ long and containing 8 introns, by screening an $M$. truncatula library (kindly provided by David Barker). Southern analysis suggested that in addition to this gene another MtN6-related gene exists in M. truncatula (data not shown).

Figure 1 also indicates that the MtN6 sequence contains one long open reading frame (ORF), encoding a putative protein of 419 amino acids (see below, however). The extent of the homology to FluG, originally discovered with partial sequencing data (Gamas et al. 1996), was enhanced with this complete sequence, as reflected by the BLAST score shown in Table 1. Indeed, a high amino acid conservation was observed, covering $90 \%$ of the MtN6 deduced sequence, but corresponding only to the first N-terminal half of FluG (411 out of 865 amino acids). The overall amino acid composition of the homologous regions of these two proteins was found to be similar, as well as their theoretical isoelectric point (5.8 for MtN6 vs 5.5 for FluG). BLAST searches of nonredundant gene and protein data bases (Table 1) revealed only one other convincing homology, with a bacterial hypothetical protein called Rv1879, discovered by sequencing of the Mycobacterium tuberculosis genome (Cole et al. 1998), and also found to be homologous to the N-terminal half of FluG. However, searches of expressed sequence tag data bases (dbest; Table 1) also revealed strong homologies with three plant sequences, shown in the multiple alignment analysis presented in Figure 2.

There are some uncertainties regarding the size of the MtN6-encoded protein(s). Indeed, three possible starting points can be envisaged, two located within the cDNA and the

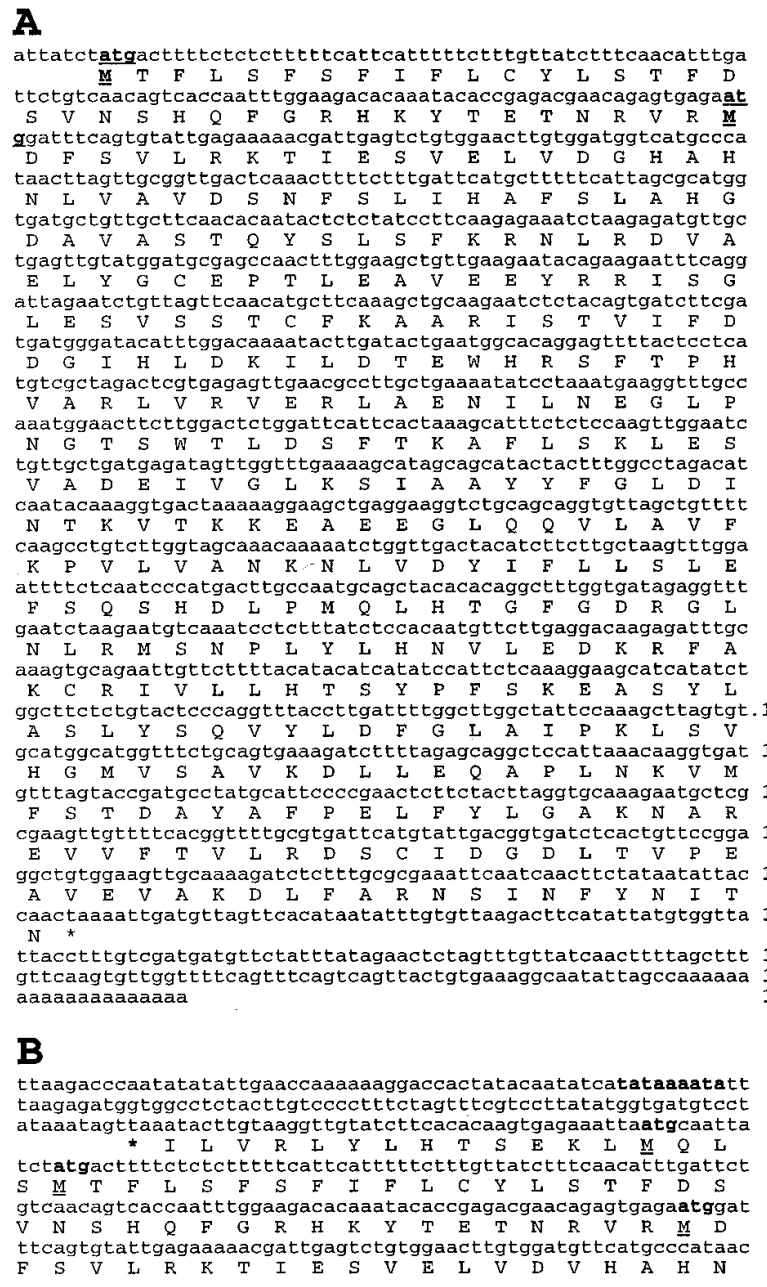

Fig. 1. A, DNA and translated sequence of the $M t N 6$ cDNA clone. B, A portion of the MtN6 gene, containing the putative translational start site(s). Possible start codons are in bold and underlined.

Table 1. Homologies found for MtN6 by interrogation of nr and dbest data bases ${ }^{\mathrm{a}}$

\begin{tabular}{lccc}
\hline Homologous sequences $^{\mathbf{b}}$ & Identities & Similarities & $\boldsymbol{E}$ value $^{\mathbf{c}}$ \\
\hline Emericella nidulans FluG protein & $119 / 412$ & $207 / 412$ & $2^{\mathrm{e}}-41$ \\
(P38094) & $(28 \%)$ & $(49 \%)$ & \\
Mycobacterium tuberculosis hypo- & $83 / 256$ & $116 / 256$ & $9^{\mathrm{e}}-19$ \\
thetical protein Rv1879 (Z97193) & $(32 \%)$ & $(44 \%)$ & \\
Oryza sativa partial sequence & $71 / 123$ & $94 / 123$ & $7^{\mathrm{e}}-35$ \\
S4994_1A (D41960) & $(57 \%)$ & $(75 \%)$ & \\
Arabidopsis thaliana cDNA clone & $54 / 108$ & $75 / 108$ & $2^{\mathrm{e}}-22$ \\
64D11T7 (T41701) & $(50 \%)$ & $(69 \%)$ & \\
Zea mays cDNA clone 6c02d01 & $44 / 86$ & $64 / 86$ & $2^{\mathrm{e}}-17$ \\
(T18405) & $(51 \%)$ & $(74 \%)$ & \\
\hline
\end{tabular}

a blastx or tblastn (Altschul et al. 1990) searches were carried out, with default parameter values.

${ }^{\mathrm{b}}$ Accession numbers are indicated in parentheses.

${ }^{\mathrm{c}}$ Probability of finding the indicated homologies by chance. 
third on the additional $5^{\prime}$ sequence present on the cloned genomic DNA, all of them in the same reading frame. Figure 1A shows the cDNA sequence with its two possible start codons in bold, the second being 38 residues downstream from the first, at a position similar to the one proposed for FluG. Figure 1B also indicates the third possible start codon, located only 4 amino acid residues upstream of the beginning of the longest cDNA ORF. It should be pointed out that although in eukaryotes the preferential initiation site is generally the one located closest to the $5^{\prime}$ end of the RNA, start codons deviating at one or more crucial positions from the optimal sequence context may allow the passage of ribosomes to further downstream start sites (leaky scanning; Fütterer and Hohn 1996). Interestingly, in the case of MtN6, the two nucleotide residues considered to be crucial around the AUG codon (a purine at -3 , and a guanine at +4 ; Fütterer and Hohn 1996; Kozak 1997) are present only in the most downstream potential start site. Moreover, it should be mentioned that coupled in vitro transcription-translation of the MtN6 cDNA with wheat germ extracts produced two proteins in similar amounts, whose sizes were consistent with the two possible start codons found in the cDNA (data not shown).

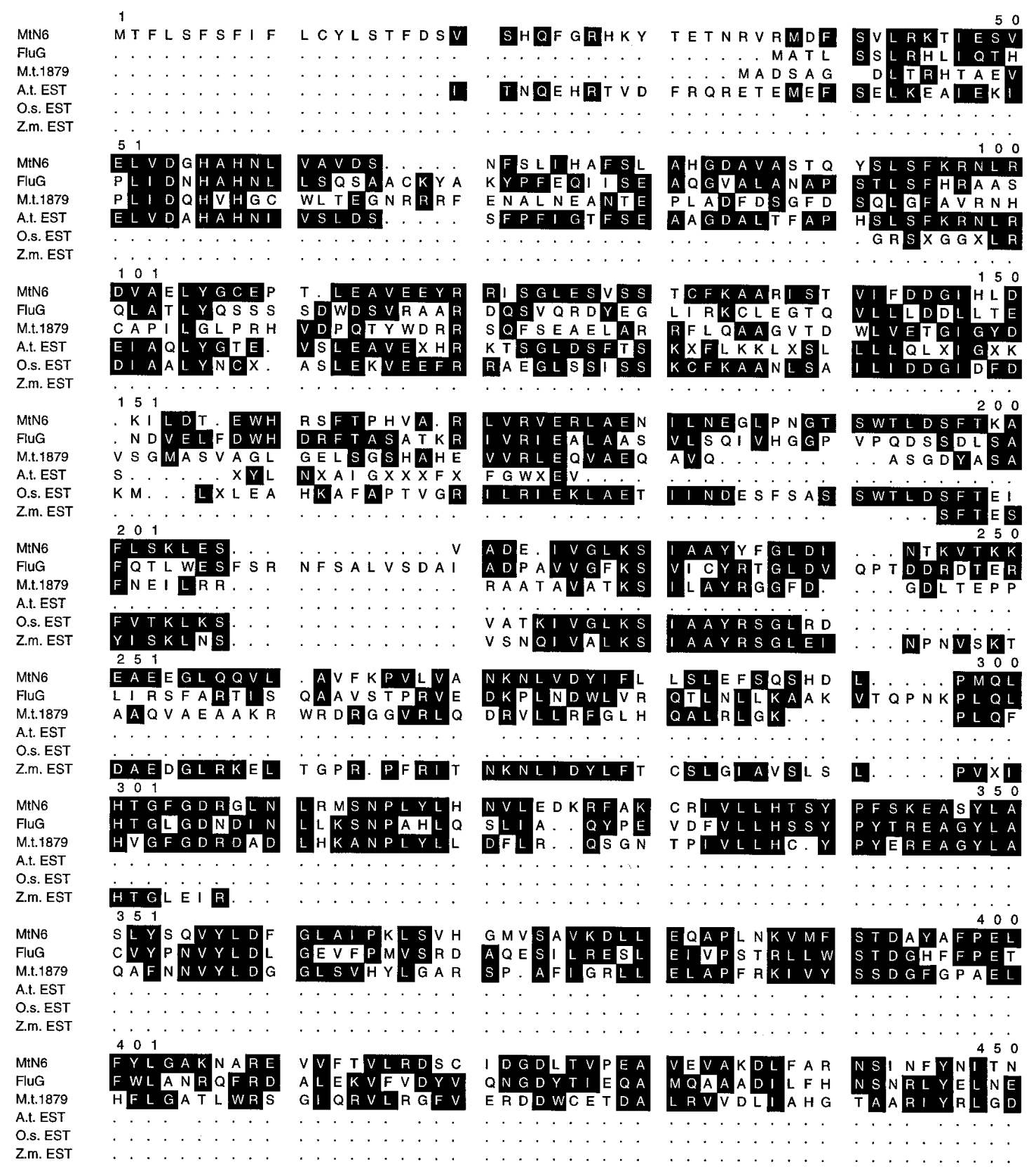

Fig. 2. Multiple alignment analysis of sequences homologous to the MtN6 putative protein. M.t.1879= Mycobacterium tuberculosis sequence; A.t.EST, O.s.EST, and Z.m.EST = translated EST (expressed sequence tag) sequences from Arabidopsis thaliana, rice, and maize, respectively. This alignment was generated with the Multalin program (Corpet 1988) with default parameter values, and the longest open reading frame found in the MtN6 cDNA. Homologies are defined here as identities, and similarities with a score equal or superior to +2 in the Multalin alignment matrix (blosom 62). 
MtN6 is a nodulin gene activated early

during $S$. meliloti-induced or spontaneous (NAR) nodule organogenesis.

Initial characterization of MtN6 expression established that this gene is transcribed at a low background level in roots, and induced in nodules as well as in $S$. meliloti-inoculated $M$. truncatula roots, as early as $24 \mathrm{~h}$ post inoculation (p.i.; Gamas et al. 1996). In this study we explored whether expression could also be observed in other organs. Figure $3 \mathrm{~A}$ shows that no induction could be detected by Northern blotting analysis in stems, flowers, and leaves. Moreover, we found that MtN6 expression was not triggered in leaves by wounding or inoculation with compatible or incompatible bacterial pathogens (Xanthomonas campestris pv. alfalfae and Pseudomonas syringae pv. pisi, respectively; data not shown).

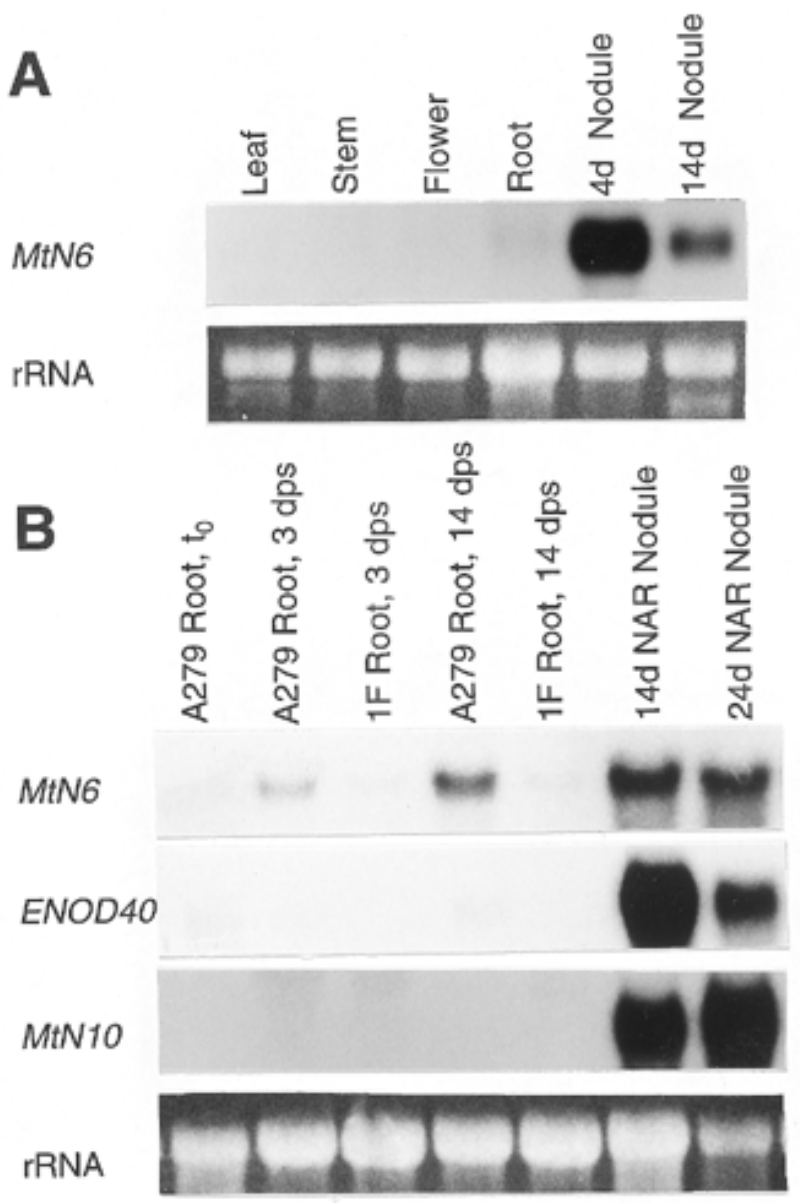

Fig. 3. Northern (RNA) analysis of MtN6 expression. Approximately 6 $\mu \mathrm{g}$ of total RNA was loaded per lane. Bottom lane shows the ethidium bromide-stained 28S rRNA band, after transfer of total RNA onto the blotting membrane. A, RNA extracted from different Medicago truncatula organs. B, RNA extracted from the $M$. sativa cortical cell division/nodulation in the absence of Rhizobium $(\mathrm{CCD} / \mathrm{NAR})^{+}$line A279, and from the $(\mathrm{CCD} / \mathrm{NAR})^{-}$line $1 \mathrm{~F}$. First five lanes are an analysis of root samples; the $\mathrm{t}_{0}$ lane corresponds to samples harvested when switching to the nitrogen-free medium; 3 and $14 \mathrm{dps}$ correspond to samples harvested after 3 and 14 days of nitrogen starvation. Emerging NAR nodules were manually removed from the 14-day root sample, to focus the analysis on nodule primordia. Last two lanes show an analysis of the RNA extracted from isolated spontaneous NAR nodules, harvested 14 or 24 days after switching to the nitrogen-free medium.
Gamas et al. (1996) also showed that MtN6-like transcripts accumulate in spontaneous NAR nodules harvested after 33 days of nitrogen starvation. We thought that it would be of interest to study the kinetics of MtN6 expression during early stages of NAR induction. We carried out a time course analysis in an $M$. sativa line called A279, particularly active for spontaneous cortical cell divisions (CCDs) and NAR organogenesis (Grosjean and Huguet 1997), two processes that are found in the same region of the root and probably represent two successive developmental stages. We used as a control a second alfalfa line, called $1 \mathrm{~F}$, in which spontaneous nodules or division foci are rarely observed (Grosjean 1997). Four types of samples were harvested and analyzed: (i) root samples collected 3 days after nitrogen starvation, at a time when only a few division foci could be observed in the root inner cortex; (ii) root samples at 14 days of starvation, when numerous nodule primordia were present in A279; (iii) isolated NAR nodules after 14 days of starvation, i.e., when they were still small (about $1 \mathrm{~mm}$ in diameter), just emerging from the roots; and (iv) NAR nodules after 24 days of starvation, when they were well developed and often multilobed.

Using this material, we compared the expression patterns of the MtN6 M. sativa homologue with those of two wellcharacterized early nodulin genes expressed in NAR nodules, namely, ENOD40 (Crespi et al. 1994) and Mscal (Coba de la Peña et al. 1997), orthologous to MtN10 (Gamas et al. 1996). Figure 3B shows that the $M$. sativa MtN6 homologue was expressed very early in the context of spontaneous CCD/NAR organogenesis, since out of the three tested markers it was the only one exhibiting clear transcript accumulation in root tissues following 3 days of nitrogen starvation.

\section{MtN6 is a novel marker for root cortical cell activation and the nodule preinfection zone.}

Having established that MtN6 is an early nodulin gene, we then decided to determine the tissue specificity of its expression. To explore the early stages of the symbiotic interaction, we made use of $S$. meliloti spot inoculation coupled with in situ hybridization. Cytological analysis indicated that in our conditions $M$. truncatula roots responded similarly to spotinoculated alfalfa (Dudley et al. 1987). Root samples were collected approximately 24,55 , and $96 \mathrm{~h}$ p.i., and 7- $\mu \mathrm{m}$-thin sections were hybridized with a ${ }^{35} \mathrm{~S}$-labeled MtN6 antisense riboprobe.

At $24 \mathrm{~h}$ p.i., the first foci of dividing cells could be observed in the inner cortex (data not shown), and in the pericycle (as mentioned in Hirsch and LaRue 1997, and in agreement with a detailed analysis recently carried out in our laboratory: A. Timmers, M.-C. Auriac, and G. Truchet, personal communication). No sign of infection could yet be detected. Figure $4 \mathrm{~A}-\mathrm{C}$ shows that at this time point a strong MtN6 hybridization signal was observed at very defined locations, exclusively in the outer cell layers of the root (Fig. 4B, double arrow head). Examination of serial root sections established that this signal was limited to a few cells, which were obviously not dividing but nevertheless showed features of cell activation, namely, a large central nucleus and amyloplast accumulation (data not shown). To make sure that this highly localized pattern of expression was not due to the fact that the bacteria were spot inoculated, a series of root samples were analyzed $24 \mathrm{~h}$ after whole root system inoculation. Although a 
much lower proportion of sections showed symbiotic responses, compared with spot inoculation, it is important to note that regions of MtN6 induction were also found to be highly localized (data not shown).
Figure 4D-I depicts three serial sections of a sample harvested at about $55 \mathrm{~h}$ p.i., representative of the expression pattern observed in several independent samples. At this stage, newly formed infection threads can be observed in the outer
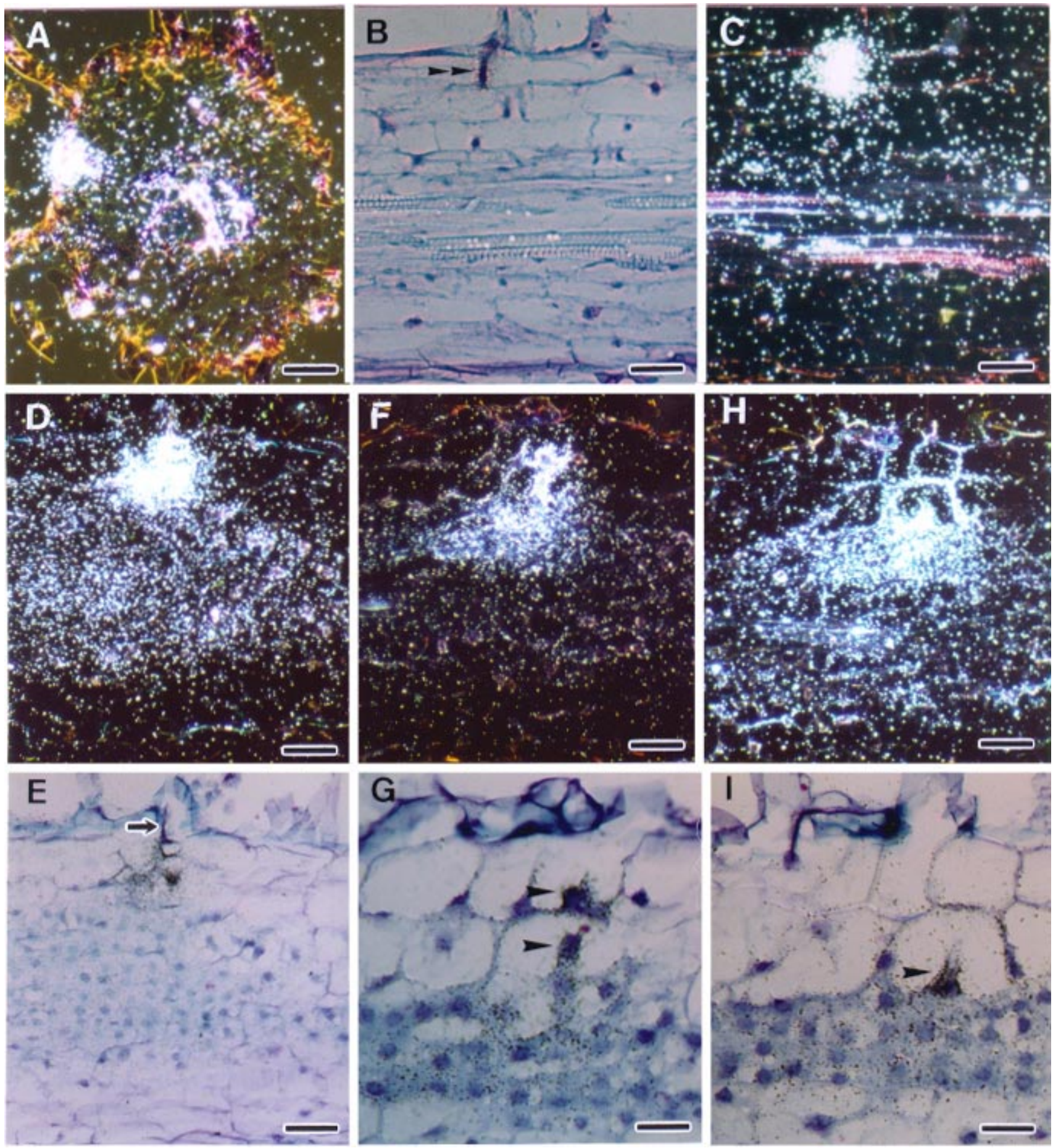

Fig. 4. In situ hybridization analysis of 7- $\mu$ m-thin root sections, with ${ }^{35}$ S-labeled $M t N 6$ antisense riboprobe. A, C, D, F, and $\mathbf{H}$, Dark-field microscopy, with the hybridization signal appearing as white dots. B, E, G, and I, Bright-field microscopy, with the hybridization signal appearing as black dots. Bars $=50 \mu \mathrm{m}$, except in $\mathbf{G}$ and $\mathbf{I}$, where bars $=25 \mu \mathrm{m}$. A, Transverse section of a Sinorhizobium meliloti spot-inoculated root, $24 \mathrm{~h}$ post inoculation (p.i.) A strong signal is seen at a very localized region, in the outer cell layers of the root. B and $\mathbf{C}$, Longitudinal section of an S. meliloti spot-inoculated root, 24 h p.i. Cell showing the MtN6 hybridization signal is marked with a double arrowhead in B. D-I, Serial longitudinal sections of an S. meliloti spotinoculated root, $55 \mathrm{~h}$ p.i. Arrow in $\mathbf{E}$ shows an infection thread just forming in the outer root cell layers. Arrowheads in $\mathbf{G}$ and $\mathbf{I}$ indicate cytoplasmic structures likely to correspond to preinfection threads. D and $\mathbf{E}$, The same section observed by dark- or bright-field microscopy, respectively, as well as $\mathbf{F}-\mathbf{G}$ and $\mathbf{H}-\mathbf{I}$. Magnification is doubled in $\mathbf{G}$ and $\mathbf{I}$, compared with $\mathbf{F}$ and $\mathbf{H}$. 
root cell layers, as shown in Figure 4E (arrow). It was found that MtN6 transcripts accumulate essentially one or two cell layers ahead of the extremity of these infection threads (Fig. 4D-I), and thus with time become proportionally more abun- dant in the inner part of the root (compare Figure 4B-C and D-I), as the infection thread grows and ramifies (data not shown). Consequently, the hybridization signal, originally restricted to a few cells in the outer cortex, broadens to reach the

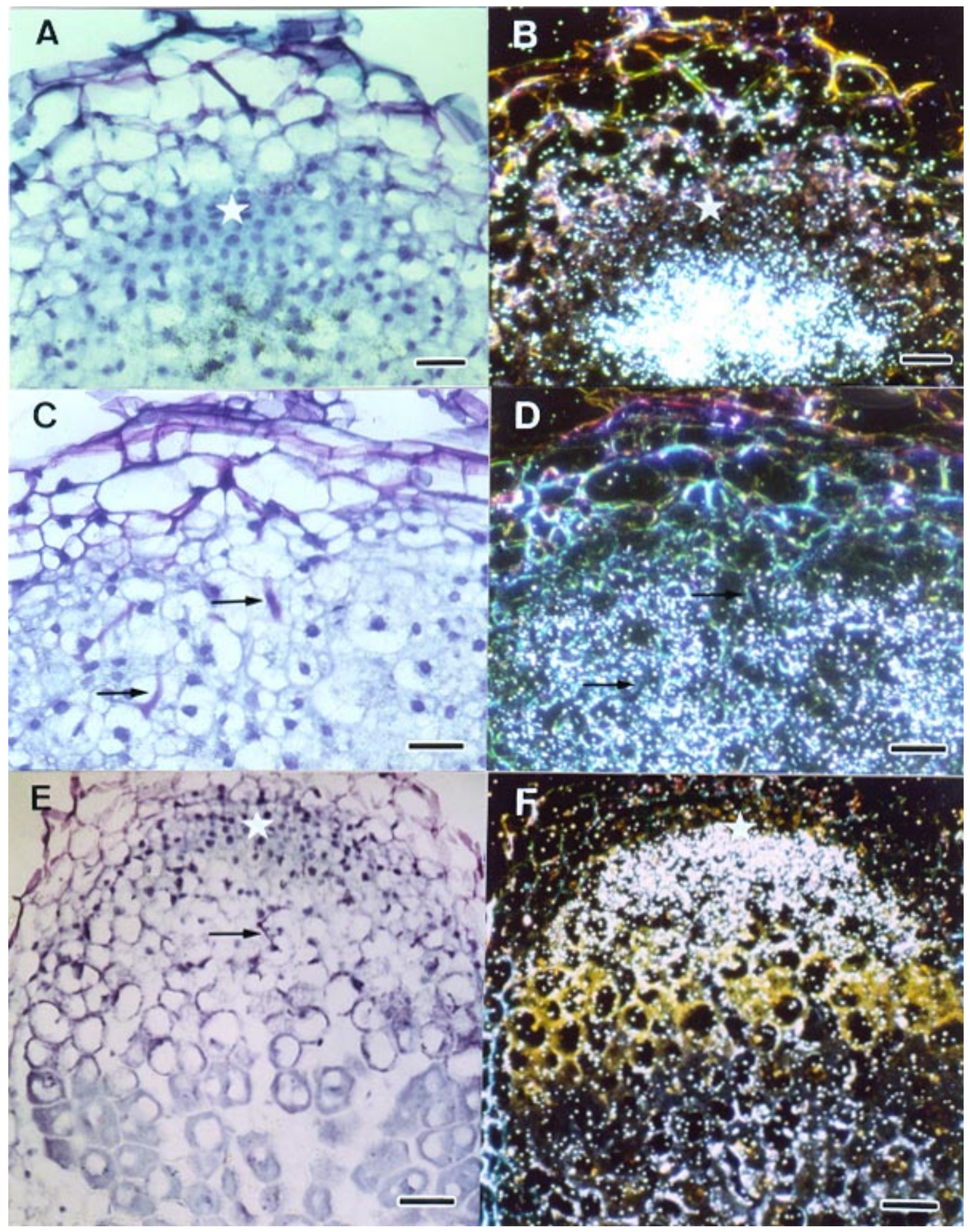

Fig. 5. In situ hybridization analysis of 7- $\mu \mathrm{m}$-thin longitudinal nodule sections, with $M t N 6$ antisense ${ }^{35}$ S-labeled riboprobe. B, C, and F, Dark-field microscopy, with the hybridization signal appearing as white dots. A, D, and $\mathbf{E}$, Bright-field microscopy of the same sections, with the hybridization signal appearing as black dots. Nodule meristem is indicated by a star; infection threads by arrows. A-D, Four-day-old nodules. Residual, nonhybridizing infection threads can be seen in the outer cortex. Bars $=50 \mu \mathrm{m}$. E-F, Fourteen-day-old nodule. Hybridization signal is exclusively found in the infection zone II of the nodule. Bars $=83 \mu \mathrm{m}$. 
dividing cells of the inner cortex, seen in the lower part of Figure 4F-I. From these series of observations, we came to the conclusion that MtN6 is expressed in cells about to be infected, which was supported by a close examination of outer cortical cells showing a strong MtN6 signal, such as those presented in Figure 4F-I. Indeed, cytoplasmic structures (marked with an arrowhead) are found in the center of these cells, in the vicinity of a large nucleus, and certainly correspond to preinfection threads (pits; van Brussel et al. 1992).

That the MtN6 signal observed in these experiments was nodulation specific and not simply related to cell activation was confirmed by the fact that no such signal could be detected in the small cells of emerging lateral roots (data not shown). An MtN6 sense riboprobe, systematically used as a negative control (at least 3 slides per time point), never gave a detectable hybridization signal (data not shown).

Figure 5 shows representative examples of in situ hybridization analyses carried out at later stages of the symbiotic interaction, with immature and mature root nodules. The young nodules (approximately 4 days old) presented in Figure 5A-D essentially consist of an apical meristem (marked with a star) and a large infection zone. At this stage, MtN6 transcripts are now absent from the outer cortical cells, and it is quite clear from Figure 5A-B that they are also excluded from the meristem. In contrast, the infection zone is strongly labeled, but it can be noted that the strongest signal is not found in cells containing infection threads, but rather in the vicinity of these cells (Fig. 5C-D, and data not shown). In more developed (2and 4-week-old) nodules with a zone I to zone IV differentiation, $M t N 6$ transcripts are essentially observed in the so-called preinfection zone (Pichon et al. 1992), i.e., in the distal part of the zone II, close to the meristem and above the infection threads (Fig. 5E-F). Some hybridization signal is also detected at a lower level in the proximal part of the zone II, whereas none is found in any other nodule tissue (data not shown).

\section{MtN6 displays a novel pattern of regulation.}

A key question raised by the study of molecular markers of development is the nature of the signal(s) activating gene expression. Thus, in $M$. truncatula it has been demonstrated that Nod factors are able to induce different early nodulin genes, such as MtENOD12, MtENOD40, or MtAnnl (Crespi et al. 1994; de Carvalho Niebel et al. 1998; Journet et al. 1994). In addition to treatments with purified Nod factors, the use of several symbiotic mutants of $S$. meliloti can also be informative in helping to define requirements for gene activation (Gamas et al. 1998; de Carvalho Niebel et al. 1998). We tested $M t N 6$ induction in response to the following four bacterial mutants: the $S$. meliloti nodA polar mutation completely inhibits Nod factor production and known symbiotic plant responses (Debellé et al. 1986); the $S$. meliloti nodH strain synthesizes Nod factors lacking the sulfate group on the reducing sugar and elicits very limited symbiotic responses in Medicago (V. Vernoud, E.-P. Journet, and D. Barker, personal communication); the double mutant nodFL produces Nod factors with an altered acyl chain and without an $O$-acetyl group, and triggers strong epidermal and cortical activation, but neither efficiently infects nor induces meristem and nodule formation, within the time scale used in our experiments (Ardourel et al. 1994; P. Gamas, unpublished observations); and, finally, the exoA strain is defective for exopolysaccharide production, and elicits small empty nodules because of infection thread abortion in the root hairs (Yang et al. 1992). Figure 6A shows that differential responses to these various Sinorhizobium strains allowed us to distinguish MtN6 from other well-known early nodulin genes, even though all of them are expressed in the infection zone II of mature nodules. Thus, in contrast to MtENOD11 (a gene whose pattern of expression is qualitatively similar to that of MtENOD12, but more strongly expressed and thus easier to study by Northern analysis; D. Barker, personal communication), MtAnnl (de Carvalho Niebel et al. 1998), or Mtenod40 (data not shown), MtN6 was not found to be activated by a nodFL mutant. MtN6 was not induced by nodA or $\operatorname{nodH}$ strains, but could be expressed in response to the exoA mutant, indicating that successful infection is not critical for its induction, which is consistent with the strong expression observed in NAR nodules (Fig. 3B). The experiment shown in Figure 6 was conducted with a super-

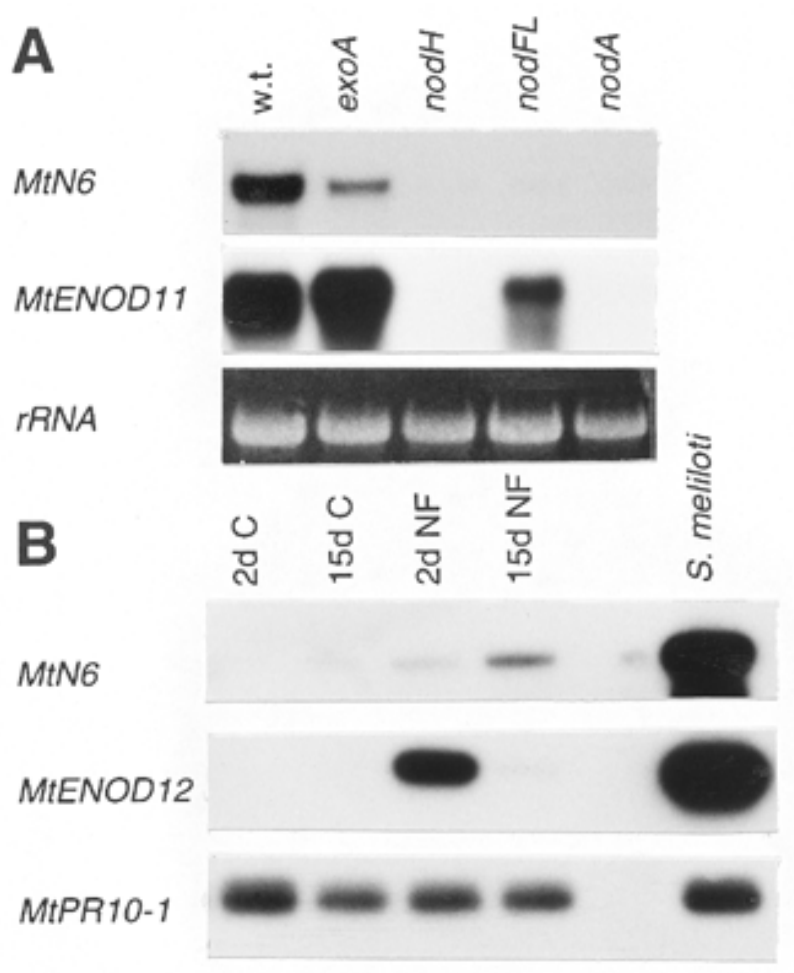

Fig. 6. Analysis of MtN6 pattern of induction in Medicago truncatula TR122, in response to (A) various Sinorhizobium strains or (B) purified Nod factors. MtN6 expression was compared with that of MtENOD11 or $M t E N O D 12$, two early nodulin genes showing similar regulation features. A, Northern (RNA) analysis with approximately $6 \mu \mathrm{g}$ of total RNA per lane. $M$. truncatula RNA was isolated from whole root systems, harvested 6 days after inoculation with wild-type (w.t.) or mutant strains of $S$. meliloti. Bottom lane shows the ethidium bromide-stained 28S rRNA band, after transfer of total RNA onto the blotting membrane. B, Reverse-transcription-polymerase chain reaction (RT-PCR) analysis of RNA extracted from roots treated for 2 or 15 days with $10^{-7} \mathrm{M}$ NodRm-IV(Ac, S, C16:2) (lanes $2 \mathrm{~d}$ NF and 15d NF), or with water (lanes $2 \mathrm{~d}$ C and 15d C). Right lane shows the signal obtained with $S$. meliloti-inoculated roots (6 days post inoculation). Amplification products, obtained after 25 (MtN6 and MtENOD12) and 20 (MtPR10-1) PCR cycles, were detected by hybridization with the corresponding ${ }^{32} \mathrm{P}$ labeled probe, after Southern blotting. No signal was detected with control samples from which reverse-transcriptase was omitted. 
nodulating mutant of $M$. truncatula, TR122 (Sagan et al. 1995), which shows enhanced induction of nodulins in response to wild-type, exoA, and nodFL strains of Sinorhizobium without qualitative modification, and is thus quite useful for Northern analysis (de Carvalho Niebel et al. 1998). The same experiments were also carried out with qualitatively similar results on wild-type plants of $M$. truncatula (data not shown).

We then investigated MtN6 response to purified Nod factors (NodRm-IV(Ac, S, C16:2), 10-7 M). Since our initial studies with Northern analysis failed to show induction (Gamas et al. 1996; P. Gamas, unpublished data), we therefore used a reverse-transcription polymerase chain reaction (RT-PCR) assay, with MtPR10-1 and MtENOD12 as positive controls for the quality of the cDNA and for Nod factor induction, respectively (Pingret et al. 1998). Figure 6B is a representative example of several independent RT-PCR experiments, from which it appears that a very low level of MtN6 induction was occasionally detected after $48 \mathrm{~h}$ of treatment, i.e., at a time when strong MtENOD12 transcript accumulation was observed. Due to the basal level of MtN6 expression in roots, it was not possible to further increase the sensitivity of detection. However, after 2 weeks of growth in the presence of Nod factors MtN6 showed a weak but more convincing induction of its expression, whereas the MtENOD12 signal substantially decreased in comparison to earlier time points (Fig. 6B and data not shown). At such a late stage, plant responses included CCDs as well as massive amyloplast accumulation, mainly in lateral roots (data not shown). In contrast to alfalfa (Truchet et al. 1991), no real nodulelike structure could be observed under our experimental conditions.

\section{DISCUSSION}

A nodulin gene is particularly useful as a tool in nodulation studies when its expression can be clearly associated to a defined developmental stage or process. In this study, we show that MtN6, a gene recently identified from M. truncatula (Gamas et al. 1996), represents an early nodulin gene likely to be directly associated with the capacity for a cell to become infected by S. meliloti. MtN6 shows several novel features that are discussed below, in terms of both regulation and sequence homologies.

\section{MtN6 is a novel marker for events preceding infection in M. truncatula.}

The use of spot inoculation coupled with in situ hybridization was very fruitful in exploring MtN6 expression at early stages of the symbiotic interaction with $S$. meliloti. It revealed that MtN6 expression is quite strong as early as $24 \mathrm{~h}$ post bacterial inoculation, in very localized regions in the outer root cell layers, in cells presenting cytological features of cell cycle activation. Examination of later stages (about 55 h p.i.) has established that these regions correspond to sites shortly to be infected. Indeed, at this time point, newly formed infection threads are observed at these sites, with the MtN6 signal being maximum just ahead of these infection threads, in outer cortical cells presenting structures likely to correspond to pits (van Brussel et al. 1992). Interestingly, this signal rapidly disappears from outer cortical cells traversed by the infection thread, indicating that accumulation of MtN6 transcripts is transient, and suggesting that MtN6 plays a role before the infection thread penetrates the cell. Consequently, a gradual displacement of the hybridization signal toward inner cell layers can be observed during the first 3 days of the symbiotic interaction. The signal broadens when reaching the inner cortex, which can be interpreted as an increasing number of cells preparing for infection, ahead of branching infection threads. In mature nodules MtN6 is expressed exclusively in the infection zone II, and preferentially in its apical part, i.e., in the region located ahead of the infection threads growing toward the nodule meristem. This localization is therefore consistent with that observed at earlier symbiotic stages.

We thus believe that MtN6 induction is a specific marker for pre-infection events, including pit formation. Pits were originally described in pea and vetch (van Brussel et al. 1992), but since then have been observed in Medicago spp., with kinetics and localization properties consistent with the pattern of MtN6 activation (A. Timmers, M.-C. Auriac, and G. Truchet, personal communication). Their differentiation is thought to result from cell cycle reactivation events with an arrest at the G2 phase, before the cells divide (Yang et al. 1994). Interestingly, the MtN6 expression pattern revealed by in situ hybridization is quite similar to the one described for $H 4$ (a marker for cells in S phase) in the outer cortex (Yang et al. 1994). However, in contrast to $H 4$, at early stages MtN6 is not expressed in inner cortical cells preparing for division, which is consistent with the idea that it is specifically associated with preparation for infection, and not simply a marker of cell activation. This conclusion is also supported by MtN6 expression in response to two Sinorhizobium mutants. Indeed, an exoA strain, which elicits abortive infection threads but normal pit formation (A. Timmers, M.-C. Auriac, and G. Truchet, personal communication) is able to induce MtN6. In contrast, a nodFL double mutant that elicits strong epidermal and cortical cell activation but no pit formation (A. Timmers, M.-C. Auriac, and G. Truchet, personal communication) does not trigger MtN6 expression.

It seems that, at early symbiotic stages, the MtN6 expression pattern presents unique features, clearly distinct from that of ENOD12, a well-known early nodulin gene described in several legumes, and generally postulated to play a role in the preinfection processes (Bauer et al. 1994; Pichon et al. 1992; Scheres et al. 1990a; see Bauer et al. 1997 for an alternative view of MsENOD12A function). In M. truncatula, ENOD12 is first transcribed in all epidermal cells of the nodulationcompetent region (Pichon et al. 1992). This type of pattern is also observed with another early nodulin gene involved in preinfection events, Mtrip-1 (Cook et al. 1995), but was never seen with MtN6 (11 independent spot-inoculated samples, i.e., at least 300 sections, see Materials and Methods), which was exclusively activated at infection sites, even when spread inoculation was used instead of spot inoculation (data not shown). In pea, ENOD12 also differs from MtN6 since it is expressed in the dividing inner cortical cells, at a stage when infection threads are not yet developed (Scheres et al. 1990a). It should be noted that the MtN6 pattern of expression is also distinct from that of early nodulins strictly associated with the infection process, such as PSENOD5 (Scheres et al. 1990b) or MtN1 (Gamas et al. 1998), none of them being expressed before the infection threads are formed. In contrast, at later stages of nodulation, the MtNG pattern is reminiscent of that of 
ENOD12 (Pichon et al. 1992; Scheres et al. 1990a) and of the annexin-encoding gene MtAnnl (de Carvalho Niebel et al. 1998) expressed ahead of growing infection threads in roots and in the infection zone II of mature nodules.

\section{Control of the MtN6 activation pathway.}

One reason for characterizing a variety of early nodulin genes is to determine the number and the nature of the signals involved in the control of the nodulation. In that light, MtN6 is interesting because it may represent the first specific marker associated with pit formation. In this study, we first analyzed $M t N 6$ expression in responses to $S$. meliloti mutants and established that MtN6 induction could be elicited by exoA mutants, but not by nodA, nodH, or nodFL strains. We then showed that plant treatments with purified Nod factors (mainly NodRm-IV(Ac, S, C16:2)) were able to induce a low level of MtN6 expression, under conditions in which other nodulin genes such as MtENOD12 (Fig. 6), MtENOD11 (data not shown), or MtAnnl (de Carvalho Niebel et al. 1998) were strongly activated. The induction of MtN6 expression by Nod factors was mainly seen at late time points, which could reflect either a slow accumulation of transcripts produced at a low level, or a late induction of transcription.

We conclude from these experiments that (i) not surprisingly, Nod factors are obligatory components, whether direct or indirect, of bacteria-induced MtN6 expression, (ii) MtN6 gene induction is not controlled via the same pathway as MtENOD11, MtENOD12, MtENOD40, or MtAnn1. Indeed, in contrast to $M t N 6$, these four genes are efficiently induced by the nodFL double mutant of $S$. meliloti, as well as by purified Nod factors.

The existence of several (at least two) perception mechanisms of Nod factors has been proposed from studies of situations in which epidermal and cortical cell activation are uncoupled from infections, due to mutations in bacterial nod genes (Ardourel et al. 1994) or in the host plant (sym2 of pea; Geurts et al. 1997). The pathway controlling infections (through the Nod factor "entry receptor"; Ardourel et al. 1994), including the pit formation, is more stringent in terms of Nod factor structure requirements than the pathway leading to root hair deformation, inner cortical cell activation ("signaling receptor"; Ardourel et al. 1994), or PsENOD12 induction (Geurts et al. 1997; Horvath et al. 1993; van Brussel et al. 1992). It seems to us that the features of MtN6 expression, in terms of both spatio-temporal pattern and response to $S$. meliloti mutants, make it a good candidate for a marker of the pathway controlling infections. Other early nodulin genes such as ENOD12, ENOD40, or MtAnnl could be induced at early symbiotic stages through the nonstringent signaling receptor, and additionally through the infection pathway at later stages, which might explain why their pattern is similar to that of MtN6 in nodules. The fact that these genes, as well as $M t N 6$, are induced in NAR nodules may indicate that several Nod factor-controlled pathways are activated during NAR organogenesis, even though it is not known whether pits are formed in this situation.

Whether MtN6 expression is directly controlled by Nod factors remains an open question, especially since MtNG is induced only weakly by purified Nod factors. MtN6 could be activated by a Nod factor-dependent process, rather than by or in addition to Nod factor molecules. One obvious possibility could be the beginning of infection itself. Indeed, it is likely that various processes are activated well before infection threads form, such as local degradation of the cell wall by secreted bacterial enzymes. However, the high level of MtN6 expression during NAR organogenesis is not consistent with this hypothesis, unless MtN6 could be induced via several pathways. The possibility that additional signal molecules are required in combination with Nod factors for strong MtN6 induction is also conceivable. It should be mentioned here that, in contrast to the situation described in pea and vetch, Nod factorinduced pit formation has not been observed in $M$. sativa or $M$. truncatula (A. Timmers, M.-C. Auriac, and G. Truchet, personal communication), which may suggest that an additional factor is required in this legume. Alternatively, it is possible that our Nod factor preparation is not perfectly adequate to activate a stringent receptor. Indeed, it cannot be excluded that the population of Nod factors produced under physiological conditions differs slightly from the molecules that we used, i.e., purified from a luteolin-induced culture of a Nod factoroverproducing strain of Sinorhizobium (Lerouge et al. 1990).

\section{What could be the connection between MtN6 and FluG proteins?}

The level of homology between FluG and MtN6 as well as the major role played by FluG in a developmental program of E. nidulans justify an exploration of the possible functional relationships between these two proteins. FluG seems to act through the synthesis of a small diffusible signal, yet to be identified, that is capable of activating a pathway leading to conidiophore formation, via a signal-transducing mechanism and a central regulatory gene, brlA (Lee and Adams 1995). It is interesting to note that, as nodulation, conidiation is sensitive to the nutritional status of the organism. Indeed, submerged cultures can be induced to sporulate by nutrient (carbon or nitrogen) starvation, fluG being required for responding to nitrogen, but not carbon, starvation (Lee and Adams 1995). Nevertheless, it is not yet established whether fluG is involved in sensing the nitrogen status of A. nidulans, or, alternatively, whether different signals act through separate but additive pathways to activate conidiation.

The FluG protein is structured in two domains, with an $\mathrm{N}$ terminal domain homologous to the MtN6 deduced protein, and a C-terminal region in which all the fluG mutations identified so far are located, demonstrating its importance for FluG function. We have been able to identify a small gene family in $M$. truncatula, encoding products highly homologous to the Cterminal domain of FluG, and possibly also to the whole FluG product for some of them, based on the size of the detected transcripts (R. Mathis, P. Gamas, and J. Cullimore, in preparation). One possibility, which will have to be evaluated in the future, is that MtN6 is able to interact with either of these protein species, to interfere positively or negatively with their action. It should be borne in mind that homologues of each FluG domain, called Rv 1879 and Rv 1878, also exist in $M y-$ cobacterium tuberculosis (Cole et al. 1998), and are present in separate ORFs whose expression is likely to be tightly coupled. Indeed, they are separated by only $3 \mathrm{bp}$, with the potential ribosome-binding site of the downstream ORF being $7 \mathrm{bp}$ before the stop codon of the upstream ORF.

It is premature to speculate more precisely on the biochemical function of MtN6, and relate it to a possible role in prepa- 
ration to infection. It is worth noting, however, that close homologues to MtN6 are likely to exist in other legumes, since cross-hybridizing transcripts of similar size were found by Northern analysis in nodule RNA from Vicia sativa and $P$. sativum ( $\mathrm{R}$. Mathis and P. Gamas, unpublished results), as well as in nonlegume plants and bacteria (data base searches; see Results). Future experiments should help us to understand the role played by this family of related proteins in such diverse organisms.

\section{MATERIALS AND METHODS}

\section{Plant growth and treatments.}

Three types of plant growth conditions were used for $M$. truncatula cv. Jemalong (Barker et al. 1990), depending on the experiment. For analysis of the RNA extracted from the whole root system (studies of responses to bacterial strains, or Nod factors), plants were grown in pouches as described in Gamas et al. (1998). For spot-inoculation experiments, they were grown on nitrogen-free Fahraeus medium (Fahraeus 1957) on $12.5 \times 12.5 \mathrm{~cm}$ dishes, whereas aeroponic growth conditions (as in Gamas et al. 1996) were chosen to obtain isolated nodules and aerial tissues. Alfalfa lines (Medicago sativa L. 'Gemini') were propagated vegetatively as described in Grosjean and Huguet (1997), and grown aeroponically to collect material, first in nitrogen-containing medium (5 mM ammonium nitrate) and then in nitrogen-free medium (as in Truchet et al. 1989) to trigger spontaneous CCDs and NAR nodule organogenesis. Cytological observations at various time points allowed us to define the portions of roots to be harvested (medium region of the primary root, i.e., excluding the oldest and youngest parts of the root; Grosjean 1997) to enrich our material in nodule primordia.

The Sinorhizobium strains used were described in Gamas et al. (1998). Each pouch (i.e., 5 plants) was inoculated, after 8 days of plant growth in the absence of combined nitrogen, with $1 \mathrm{ml}$ of bacteria resuspended at an $\mathrm{OD}_{600}$ of 0.015 in the growth medium. Experiments were performed twice with wild-type $M$. truncatula and with the TR122 supernodulating mutant of M. truncatula (Sagan et al. 1995). Results were qualitatively similar in both genotypes, with stronger levels of induction in TR122, as observed for all tested nodulin markers (de Carvalho Niebel et al. 1998; M. C. Boudet and P. Gamas, unpublished results). Nod factor treatments were carried out on plants of the same age, with $1 \mathrm{ml}$ of solution per pouch. Two different Nod factor preparations (a mixture of Nod factors with a majority of NodRm-IV(Ac, S, C16:2), purified from luteolin-induced $R$. meliloti 2011 pGMI149, as in Lerouge et al. 1990) were used, at a $10^{-7} \mathrm{M}$ final concentration, with similar results.

Spot inoculation was carried out on 8-day-old plants, with $0.2 \mu \mathrm{l}$ of bacteria resuspended in $1 \%$ carboxymethylcellulose wt/vol (Stokkermans and Peters 1994) at an $\mathrm{OD}_{600}$ of 0.1 . Spots were realized at the site of emerging root hairs (i.e., 5 to $10 \mathrm{~mm}$ away from the root tip), and marked with charcoal. Root segments covering about $3 \mathrm{~mm}$ on each side of the spot were harvested for sections. Approximately $80 \%$ of the roots responded to the treatment in our conditions. One control experiment was conducted with spread inoculation, done with $200 \mu \mathrm{l}$ of a bacterial suspension at the same OD. Root segments $(8 \mathrm{~mm}$ long) were harvested $24 \mathrm{~h}$ p.i. from 16 plants, sectioned transversally or longitudinally, and analyzed by in situ hybridization. Two of them showed MtN6 activation.

\section{RNA and DNA analysis.}

Total RNA was extracted from frozen plant tissue following the procedure of Jackson and Larkins (1976). Northern and Southern analyses were conducted with Nytran Plus membranes according to the manufacturer's instructions (Schleicher \& Schuell, Dassel, Germany), with DNA radioactive probes prepared with the Ready-To-Go kit (Pharmacia, Uppsala, Sweden) and purified on microspin $200 \mathrm{HR}$ columns (Pharmacia).

RT-PCR analysis was carried out as described by Pingret et al. (1998), on DNase-treated RNA samples. The number of PCR cycles was determined for each primer combination in order to analyze amplification products corresponding to the exponential phase of the reaction. For MtN6, 25 cycles were carried out, consisting of $30 \mathrm{~s}$ at $94^{\circ} \mathrm{C}, 30 \mathrm{~s}$ at $57^{\circ} \mathrm{C}$, and $1 \mathrm{~min}$ at $72^{\circ} \mathrm{C}$, and with the following primers: $5^{\prime}$-TGGTGATGCT GTTGCTTC-3' (forward); 5'-CATGAATCACGCAAAACC$3^{\prime}$ (reverse). The cDNA and the gene amplification products could easily be distinguished because of the presence of several introns between the two primer sites (data not shown). Experiments were conducted three times, with similar results. Wild-type $M$. truncatula cv. Jemalong J5 was tested for Nod factor induction, as well as the TR122 supernodulating mutant (Sagan et al. 1995). Induction was weaker with the wild-type than with TR122 plants.

DNA sequencing was carried out on both strands of plasmid DNA, with a Perkin-Elmer/ABI 373A automatic sequencer (Foster City, CA). Sequence data were analyzed with University of Wisconsin Genetic Computer Group (GCG) software. Homology searches were carried out through the NCBI BLAST server. Sequence alignments were done with the Multalin program (Corpet 1988).

\section{In situ hybridization.}

In situ hybridization was conducted following the procedure described in Gamas et al. (1998), with a 3- to 4-week exposure. Samples were treated with $0.2 \%$ eosin B (in absolute ethanol) just before the ethanol-xylene treatments, in order to visualize them more easily when embedded in paraplast. Sections were observed with a Zeiss axiophot light microscope. Observations were made on samples from two independent experiments, with 7 to 12 slides per time point (each corresponding to an independent sample, and representing at least 30 serial sections).

\section{ACKNOWLEDGMENTS}

We thank David Barker, Julie Cullimore, and Georges Truchet for critical reading of this manuscript. We are grateful to Georges Truchet for sharing unpublished information. We are also grateful to Fernanda de Carvalho Niebel, Andreas Niebel (our laboratory), and Katharina Pawlowski (Institut für Biochemie der Pflanze, Göttingen, Germany), for providing RNA samples, and to Muriel Sagan and Gérard Duc (INRA, Dijon) for providing $M$. truncatula seeds. We thank Vanessa Vernoud (our laboratory) for technical advice on RT-PCR experiments, and Ton Timmers and Georges Truchet for interesting discussions on cytological analysis. Many thanks to Nicole Lescure, Francis Carbonne, and Karin Liebe for the automatic sequencing. R. M. was supported by a grant from the Ministère de l'Education Nationale, de la Recherche et de la Technologie. Financial support was provided by CNRS (programme 
génome 1998) and INRA (AIP Biologie du Développement 1995-1997; programme Génome et Fonctions 1998).

\section{LITERATURE CITED}

Altschul, S. F., Gish, W., Miller, W., Myers, E. W., and Lipman, D. 1990. Basic local alignment search tool. J. Mol. Biol. 215:403-410.

Ardourel, M., Demont, N., Debellé, F., Maillet, F., de Billy, F., Promé, J.-C., Dénarié, J., and Truchet, G. 1994. Rhizobium meliloti lipooligosaccharide nodulation factors: Different structural requirements for bacterial entry into target root hair cells and induction of plant symbiotic developmental responses. Plant Cell 6:1357-1374.

Bauer, P., Crespi, M. D., Szecsi, J., Allisson, L. A., Schultze, M., Ratet, P., Kondorosi, A., and Kondorosi, E. 1994. Alfalfa Enod12 genes are differentially regulated during nodule development by nod factors and Rhizobium invasion. Plant Physiol. 105:585-592.

Bauer, P., Poirier, S., Ratet, P., and Kondorosi, A. 1997. MsEnod12A expression is linked to meristematic activity during development of indeterminate and determinate nodules and roots. Mol. Plant-Microbe Interact. 10:39-49.

Cheng, H.-P. and Walker, G. 1998. Succinoglycan is required for initiation and elongation of infection threads during nodulation of alfalfa by Rhizobium meliloti. J. Bacteriol. 180:5183-5191.

Coba de la Peña, T. C., Frugier, F., McKhann, H. I., Bauer, P., Brown, S., Kondorosi, A., and Crespi, M. 1997. A carbonic anhydrase gene is induced in the nodule primordium and its cell-specific expression is controlled by the presence of Rhizobium during development. Plant $\mathbf{J}$. 11:407-420.

Cohn, J., Day, R. B., and Stacey, G. 1998. Legume nodule organogenesis. Trends Plant Sci. 3:105-110.

Cole, S. T., Brosch, R., Parkhill, J., Garnier, T., Churcher, C., Harris, D., Gordon, S. V., Eiglmeier, K., Gas, S., Barry, C. E., Tekaia, F., Badcock, K., Basham, D., Brown, D., Chillingworth, T., Connor, R., Davies, R., Devlin, K., Feltwell, T., Gentles, S., Hamlin, N., Holroyd, S., Hornsby, T., Jagels, K., and Barrell, B. G. 1998. Deciphering the biology of Mycobacterium tuberculosis from the complete genome sequence. Nature 393:537-544.

Cook, D., Dreyer, D., Bonnet, D., Howell, M., Nony, E., and VandenBosch, K. 1995. Transient induction of a peroxidase gene in Medicago truncatula precedes infection by Rhizobium meliloti. Plant Cell 7:43-55.

Corpet, F. 1988. Multiple sequence alignment with hierarchical clustering. Nucleic Acids Res. 16:10881-10890.

Crespi, M. D., Jurkevitch, E., Poiret, M., d'Aubenton-Carafa, Y., Petrovics, G., Kondorosi, E., and Kondorosi, A. 1994. enod40, a gene expressed during nodule organogenesis, codes for a non-translatable RNA involved in plant growth. EMBO J. 13:5099-5112.

de Carvalho Niebel, F., Lescure, N., Cullimore, J. V., and Gamas, P. 1998. The Medicago truncatula MtAnn1 gene encoding an annexin is induced by Nod factors and during the symbiotic interaction with $R h i$ zobium meliloti. Mol. Plant-Microbe Interact. 11:504-513.

Debellé, F., Rosenberg, C., Vasse, J., Maillet, F., Martinez, E., Dénarié, J., and Truchet, G. 1986. Assignment of symbiotic developmental phenotypes to common and specific (nod) genetic loci of Rhizobium meliloti. J. Bacteriol. 168:1075-1086.

Dénarié, J., Debellé, F., and Promé, J.-C. 1996. Rhizobium lipochitooligosaccharide nodulation factors: Signaling molecules mediating recognition and morphogenesis. Annu. Rev. Biochem. 65:503535.

Dudley, M., Jacobs, T., and Long, S. 1987. Microscopic studies of cell divisions induced in alfalfa roots by Rhizobium meliloti. Planta 171: 289-301.

Fahraeus, G. 1957. The infection of white clover root hairs by nodule bacteria studied by a simple slide technique. J. Gen. Microbiol. 16: 374-381.

Frugier, F., Kondorosi, A., and Crespi, M. 1998. Identification of novel putative regulatory genes induced during alfalfa nodule development with a cold-plaque screening procedure. Mol. Plant-Microbe Interact. 11:358-366.

Fütterer, J., and Hohn, T. 1996. Translation in plants-rules and exceptions. Plant Mol. Biol. 32:159-189.

Gamas, P., de Billy, F., and Truchet, G. 1998. Symbiosis-specific expression of two Medicago truncatula nodulin genes, MtN1 and MtN13, encoding products homologous to plant defense proteins. Mol. PlantMicrobe Interact. 11:393-403.

Gamas, P., de Carvalho Niebel, F., Lescure, N., and Cullimore, J. V. 1996. Use of a subtractive hybridization approach to identify new Medicago truncatula genes induced during root nodule development. Mol. Plant-Microbe Interact. 9:233-242.

Geurts, R., Heidstra, R., Hadri, A.-E., Downie, A., Franssen, H., van Kammen, A., and Bisseling, T. 1997. Sym2 of pea is involved in a nodulation factor-perception mechanism that controls the infection process in the epidermis. Plant Physiol. 115:351-359.

Goormachtig, S., Lievens, S., van de Velde, W., Van Montagu, M., and Holsters, M. 1998. Srchi13, a novel early nodulin from Sesbania rostrata, is related to acidic class III chitinases. Plant Cell 10:905-915.

Goormachtig, S., Valerio-Lepiniec, M., Szczyglowski, K., Van Montagu, M., Holsters, M., and de Bruijn, F. J. 1995. Use of differential display to identify novel Sesbania rostrata genes enhanced by Azorhizobium caulinodans infection. Mol. Plant-Microbe Interact. 8:816-824.

Greene, E. A., Erard, M., Dedieu, A., and Barker, D. G. 1998 MtENOD16 and 20 are members of a family of phytocyanin-related early nodulins. Plant Mol. Biol. 36:775-783.

Grosjean, C. 1997. Aspects physiologiques, moléculaires et génétiques de la nodulation en l'absence de Rhizobium chez la luzerne (Medicago sativa L.). Ph.D. thesis. Université Paul Sabatier, Toulouse, France.

Grosjean, C., and Huguet, T. 1997. A persistent meristem is formed in nodular structures elicited by Nod factors or by a Rhizobium meliloti exopolysaccharide mutant in alfalfa plants which nodulate spontaneously. Plant Sci. 127:215-225.

Heidstra, R., and Bisseling, T. 1996. Nod factor-induced host responses and mechanisms of nod factor perception. New Phytol. 133:25-43.

Heidstra, R., Nilsen, G., Martinez-Abarca, F., van Kammen, A., and Bisseling, T. 1997. Nod factor-induced expression of leghemoglobin to study the mechanism of $\mathrm{NH}_{4} \mathrm{NO}_{3}$ inhibition on root hair deformation. Mol. Plant-Microbe Interact. 10:215-220.

Hirsch, A. 1992. Tansley review no. 40. Developmental biology of legume nodulation. New Phytol. 122:211-237.

Hirsch, A., and LaRue, T. 1997. Is the legume nodule a modified root or stem or an organ sui generis? Crit. Rev. Plant Sci. 16:361-392.

Horvath, B., Heidstra, R., Lados, M., Moerman, M., Spaink, H. P., Promé J.-C., van Kammen, A., and Bisseling, T. 1993. Lipooligosaccharides of Rhizobium induce infection-related early nodulin gene expression in pea root hairs. Plant J. 4:727-733.

Jackson, A. D., and Larkins, B. A. 1976. Influence of ionic strength, pH, and chelation of divalent metals on isolation of polyribosomes from tobacco leaves. Plant Physiol. 57:5-10.

Journet, E. P, Pichon, M., Dedieu, A., de Billy, F., Truchet, G., and Barker, D. G. 1994. Rhizobium meliloti Nod factors elicit cell-specific transcription of the ENOD12 gene in transgenic alfalfa. Plant J. 6:241249.

Kijne, J. 1992. The Rhizobium infection process. Pages 348-397 in: Biological Nitrogen Fixation. G. Stacey, H. Evans, and R. Burris, eds. Chapman and Hall, London.

Kozak, M. 1997. Recognition of AUG and alternative initiator codons is augmented by $\mathrm{G}$ in position +4 but is not generally affected by the nucleotides in positions +5 and +6 . EMBO J 16:2482-2492.

Lee, B. N., and Adams, T. H. 1994. The Aspergillus nidulans fluG gene is required for production of an extracellular developmental signal and is related to procaryotic glutamine synthetase I. Genes Dev. 8:641-651.

Lee, B. N., and Adams, T. H. 1995. fluG and flbA function interdependently to initiate conidiophore development in Aspergillus nidulans through $b r l A b$ activation. EMBO J. 15:299-309.

Lerouge, P., Roche, P., Faucher, C., Maillet, F., Truchet, G., Promé, J.C., and Dénarié, J. 1990. Symbiotic host-specificity of Rhizobium meliloti is determined by a sulphated and acylated glucosamine oligosaccharide signal. Nature 344:781-784.

Long, S. R. 1996. Rhizobium symbiosis: Nod factors in perspective. Plant Cell 8:1885-1898.

Mylona, P., Pawlowski, K., and Bisseling, T. 1995. Symbiotic nitrogen fixation. Plant Cell 7:869-885.

Pawlowski, K. 1997. Nodule-specific gene expression. Physiol. Plant. 99:617-631.

Pichon, M., Journet, E. P, Dedieu, A., de Billy, F., Truchet, G., and Barker, D. G. 1992. Rhizobium meliloti elicits transient expression of 
the early nodulin gene ENOD12 in the differentiating root epidermis of transgenic alfalfa. Plant Cell 4:1199-1211.

Pingret, J. L., Journet, E. P., and Barker, D. G. 1998. Rhizobium Nod factor signaling. Evidence for a $\mathrm{g}$ protein-mediated transduction mechanism. Plant Cell 10:659-672.

Sagan, M., Morandi, D., Tarenghi, E., and Duc, G. 1995. Selection of nodulation and mycorrhizal mutants in the model plant Medicago truncatula (Gaertn.) after $\gamma$-ray mutagenesis. Plant Sci. 111:63-71.

Scheres, B., van de Wiel, C., Zalensky, A., Horvath, B., Spaink, H., van Eck, H., Zwartkruis, F., Wolters, A.-M., Gloudemans, T., van Kammen, A., and Bisseling, T. 1990a. The ENOD12 gene product is involved in the infection process during the Pea-Rhizobium interaction. Cell 60:281-294.

Scheres, B., van Engelen F., van der Knaap, E., and van de Wiel, C. 1990b. Sequential induction of nodulin gene expression in the developing pea nodule. Plant Cell 2:687-700.

Schultze, M., and Kondorosi, A. 1996. The role of lipochitooligosaccharides in root nodule organogenesis and plant cell growth. Curr. Opin. Genet. Dev. 6:631-638.

Spaink, H. P. 1996. Regulation of plant morphogenesis by lipo-chitin oligosaccharides. Crit. Rev. Plant Sci. 15:559-582.

Stokkermans, T. J., and Peters, N. K. 1994. Bradyrhizobium elkanii lipooligosaccharide signals induce complete nodule structures on Glycine soja Siebold et Zucc. Planta 193:413-420.

Szczyglowski, K., Hamburger, D., Kapranov, P., and de Bruijn, F. J. 1997. Construction of a Lotus japonicus late nodulin expressed sequence tag library and identification of novel nodule-specific genes. Plant Physiol. 114:1335-1346.
Truchet, G., Barker, D. G., Camut, S., de Billy, F., Vasse, J., and Huguet, T. 1989. Alfalfa nodulation in the absence of Rhizobium. Mol. Gen. Genet. 219:65-68.

Truchet, G., Roche, P., Lerouge, P., Vasse, J., Camut, S., de Billy, F., Promé, J.-C., and Dénarié, J. 1991. Sulphated lipo-oligosaccharide signals of Rhizobium meliloti elicit root nodule organogenesis in alfalfa. Nature 351:670-673.

van Brussel, A. A. N., Bakhuisen, R., van Spronsen, P. C., Spaink, H. P., Tak, T., Lugtenberg, B. J. J., and Kijne, J. W. 1992. Induction of preinfection thread structures in the leguminous host plant by mitogenic lipo-oligosaccharides of Rhizobium. Science 257:70-72.

van Rhijn, P., Fang, Y., Galili, S., Shaul, O., Atzmon, N., Wininger, S., Eshed, Y., Lum, M., Li, Y., To, V., Fujishige, N., Kapulnik, Y., and Hirsch, A. M. 1997. Expression of early nodulin genes in alfalfa mycorrhizae indicates that signal transduction pathways used in forming arbuscular mycorrhizae and Rhizobium-induced nodules may be conserved. Proc. Natl. Acad. Sci. USA 94:5467-5472.

Vasse, J., de Billy, F., Camut, S., and Truchet, G. 1990. Correlation between ultrastructural differentiation of bacteroids and nitrogen fixation in alfalfa nodules. J. Bacteriol. 172:4295-4306.

Yang, C., Signer, E. R., and Hirsch, A.M. 1992. Nodules initiated by Rhizobium meliloti exopolysaccharide mutants lack a discrete, persistent nodule meristem. Plant Physiol. 98:143-151.

Yang, W. C., de Blank, C., Meskiene, I., Hirt, H., Bakker, J., van Kammen, A., Franssen, H., and Bisseling, T. 1994. Rhizobium Nod factors reactivate the cell cycle during infection and nodule primordium formation, but the cycle is only completed in primordium formation. Plant Cell 6:1415-1426. 